A. Kühn 1 A. Nieters ${ }^{2} \cdot$ A. Köttgen ${ }^{3} \cdot$ O.N. Goek ${ }^{3} \cdot$ K. Michels ${ }^{3} \cdot$ U. Nöthlings ${ }^{4}$.

G. Jacobs ${ }^{5} \cdot$ C. Meisinger ${ }^{6} \cdot$ F. Pessler ${ }^{7,8} \cdot$ M.F. Akmatov ${ }^{7,8} \cdot$ J. Kühnisch $^{9}$. S. Moebus ${ }^{10}$.

E. Glocker ${ }^{2} \cdot$ S. Naus ${ }^{2} \cdot$ M. Keimling ${ }^{11} \cdot$ M. Leitzmann ${ }^{11}$. J. Linseisen ${ }^{1} \cdot$ H. Sarioglu ${ }^{12}$.

C. von Toerne ${ }^{12}$ - S.M. Hauck ${ }^{12}$ H. Wallaschofski ${ }^{13}$ - H.E. Wichmann ${ }^{1} \cdot$ T. Illig $^{1,14}$

${ }^{1}$ Helmholtz Zentrum Muenchen-German Research Center for Environmental

Health $(\mathrm{GmbH})$, Institute of Epidemiology I, Neuherberg, Germany

${ }^{2}$ Center for Chronic Immunodeficiency, University Medical Center Freiburg, Freiburg, Germany

${ }^{3}$ Dept. of Internal Medicine IV, University Medical Center Freiburg, Freiburg, Germany

${ }^{4}$ Institute of Nutritional and Food Sciences, Rheinische Friedrich-

Wilhelms-University of Bonn, Bonn, Germany

${ }^{5}$ Institute for Epidemiology, Biobank popgen, Christian-Albrechts-University of Kiel, Kiel, Germany

${ }^{6}$ Helmholtz Zentrum Muenchen, Institute of Epidemiology II, German Research

Center for Environmental Health (GmbH), Neuherberg, Germany

${ }^{7}$ Helmholtz Centre for Infectious Research, Braunschweig, Germany

${ }^{8}$ TWINCORE Center for Experimental and Clinical Infection Research, Hannover, Germany

${ }^{9}$ Clinic of Ludwig Maximilians University, München, Germany

${ }^{10}$ Institute of Medical Computer Science, Biometry and Epidemiology,

Universitätsklinikum Essen, Essen, Germany

${ }^{11}$ Institute of Epidemiology and Preventive Medicine, University of Regensburg, Regensburg, Germany

${ }^{12}$ Helmholtz Zentrum Muenchen, German Research Center for Environmental

Health (GmbH), Research Unit Protein Science, Neuherberg, Germany

${ }^{13}$ Institute of Clinical Chemistry and Laboratory Medicine, Ernst-Moritz-

Arndt-University of Greifswald, Greifswald, Germany

${ }^{14}$ Hannover Medical School, Hannover Unified Biobank (HUB), Hannover, Germany

\title{
Feasibility and quality development of biomaterials in the pretest studies of the German National Cohort
}

The collection of biomaterials for future phenotyping at the molecular level is a basic component central to the German National Cohort (GNC). Such molecular phenotyping requires both a comprehensive array of biomaterials and optimally preserved quality, uncompromised by the needs of high-throughput technology and the practical constraints of varying field conditions. The protocols for blood sampling and storage of aliquots of plasma, serum, intact lymphocytes, erythrocytes, urine, saliva, nasal swabs and stool samples in a central biorepository with decentralized back-up storage were designed to permit the greatest flexibility in future laboratory analyses. Optimal preservation of quality relies on minimizing pre-analytical artefacts that may be incurred during specimen collection, primary processing, transport and/or storage of the samples. Suggestions for receiving good sample quality were also elaborated by several "Good practices" or "Best practices", but deal mostly with aspects concerning biobanking in general $[3,8]$. However, the here developed high standards on sample quality are not comparable to other multicentre studies $[6,7]$.

The collection of biomaterials in combination with extensive information from questionnaires and medical examinations represent central components of the study. Using combinations of such information-repeated over time-makes it possible to specifically address pathways of disease development providing clues to the biological mechanisms that may explain any observed relationships. Biomarker measurements will cover domains as diverse as nutrition and metabolism, hormonal and other physiological effects of chronic psychological stress, viral and bacterial infections, immune status, genetics and epigenetics.

In the German National Cohort, the repeated collection of measurements and biomaterials both in the short term, in calibration substudies, and in the medium term through 5-year repeat visits of all study participants will enable quantitative estimates of relative risks accurately.

Large-scale prospective cohort studies with highly standardized and valid phenotyping and the availability of a broad spectrum of high quality biomaterials provide a valuable resource for evaluating 


\begin{tabular}{|l|l|}
\hline $\begin{array}{l}\text { HelmholtzZentrum münchen } \\
\text { Deutsches Forschungszentrum für Gesundheit und Umwelt }\end{array}$ & Organisationshandbuch: \\
\hline VA-BIOMAT-01 & Biomaterialien - Pretest 2, Nationale Kohorte \\
Version 1.8 vom 11.10.2012 & \\
\hline
\end{tabular}

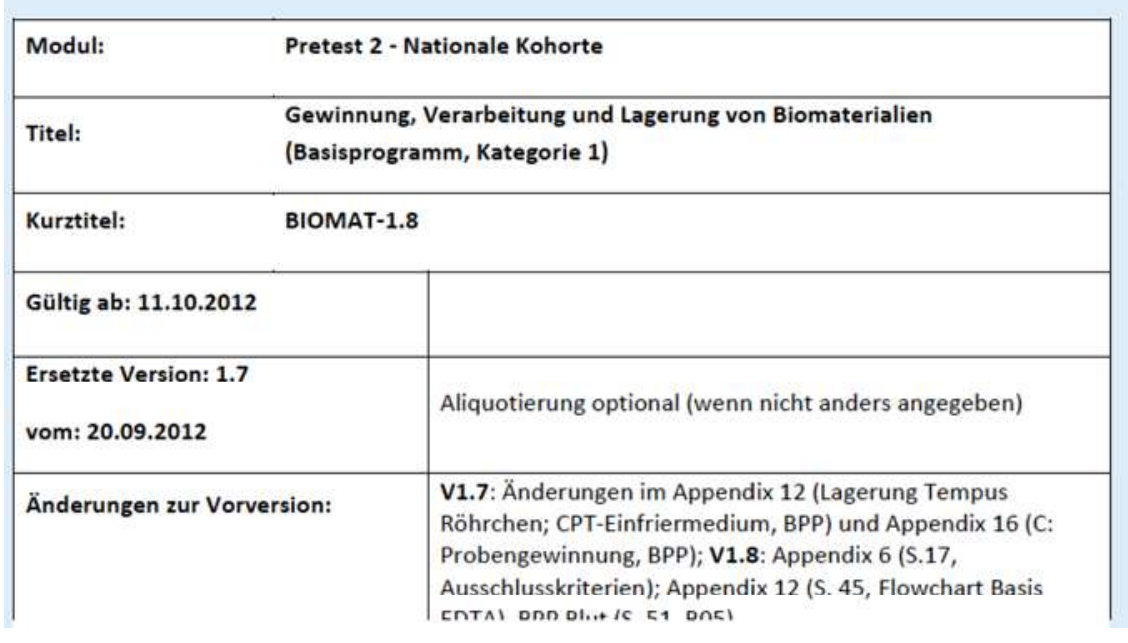

Fig. 1 Example of SOP manual developed for pretest 2

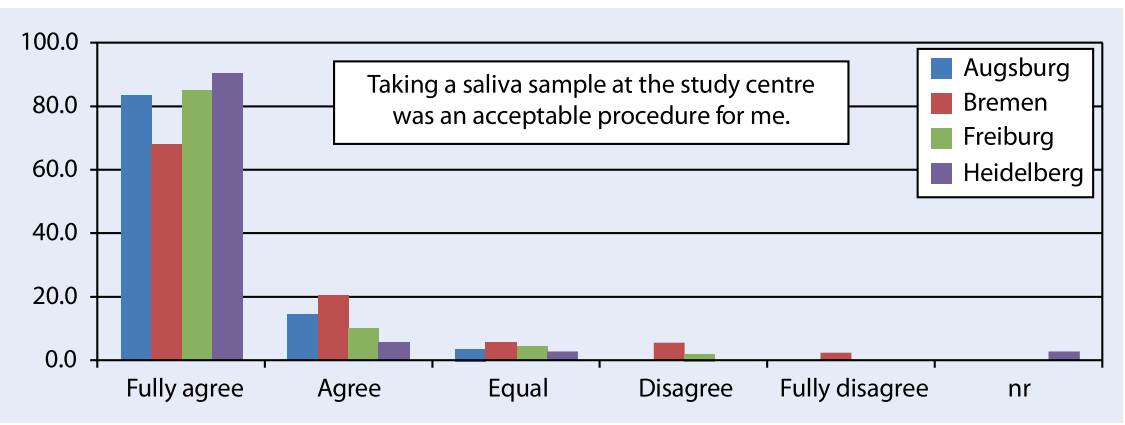

Fig. $2 \Delta$ Acceptance of saliva sample recovery in the interviewed populations (pretest 1)

candidate biomarkers for the early detection of disease. To ensure a high quality of phenotyping at the molecular level for future studies, a comprehensive array of biomaterials must be available in optimal quality. To achieve this, pre-analytical artefacts that could occur during specimen collection, primary processing, transportation and storage of the samples need to be minimized [1].

The aim of the study was in pretest 1 the (a) feasibility of sample collection and sample preparation, (b) quality control of biomarkers and (c) quality control of samples using a proteomics approach. Pretest 2 addressed mainly the recruitment of study participants for the specific projects and testing of the recruitment and proposed examination procedures in

\section{Materials and methods}

Sample collection as well as sample preparation up to freezing at $-80^{\circ} \mathrm{C}$ were performed according to standardized SOPs (- Fig. 1) at all ten participating study sites (pretest I). Biomaterials (- Table 1: blood, urine, saliva, stool, nasal and oropharyngeal swabs) were collected in a harmonized manner according to current SOPs using standardized disposables, laboratory equipment and storage materials. The SOPs included instructions for sample acquisition, preparation, storage, transportation and documentation to obtain the highest quality and to avoid artefacts resulting from incorrect or inefficient sample handling. Urine samples were investigated using Siemens Clinitek Microalbumin 9 stix, followed by automated reading using a Clinitek Status Plus Device.

In pretest study 2 , all biomaterials were collected from a minimum of 20 subjects at the 18 study sites that will participate in the main study of the German National Cohort. The study sites were asked to assess the feasibility of biomaterial collection and to develop a study time plan (- Table 2). Personnel with experience in blood collection/biomaterial collection (study nurses) and lab processes (technical assistants) was needed. The training time including certification was 1-2 days.

Study sites collected biomaterials from different numbers of participants. In total, biomaterials were collected from 599 participants according to standardized SOPs and the obtained data were entered into a common database. Informed consent in accordance with the responsible ethics committees was obtained from all participants.

Additionally, questionnaires/protocols were developed either in paper form or electronically to document parameters such as time (e.g. of sample collection, preparation or freezing), volumes and feasibility of sample retrieval (response rates, acceptance).

\section{Results}

Within the pretest studies, different aspects concerning sample collection, preparation and quality control were investigated. Sample collection took place 
A. Kühn · A. Nieters · A. Köttgen · O.N. Goek · K. Michels · U. Nöthlings · G. Jacobs · C. Meisinger · F. Pessler · M.F. Akmatov · J. Kühnisch · S. Moebus · E. Glocker · S. Naus · M. Keimling · M. Leitzmann · J. Linseisen · H. Sarioglu · C. von Toerne · S.M. Hauck · H. Wallaschofski · H.E. Wichmann · T. Illig

\section{Feasibility and quality development of biomaterials in the pretest studies of the German National Cohort}

\section{Abstract}

Background. The German National Cohort (GNC) is designed to address research questions concerning a wide range of possible causes of major chronic diseases (e.g. cancer, diabetes, infectious, allergic, neurologic and cardiovascular diseases) as well as to identify risk factors and prognostic biomarkers for early diagnosis and prevention of these diseases. The collection of biomaterials in combination with extensive information from questionnaires and medical examinations represents one of the central study components.

Objectives. In two pretest studies of the German National Cohort conducted between 2011 and 2013, a range of biomaterials from a defined number of participants was collected. Ten study centres were involved in pretest 1 and 18 study centres were involved in pretest 2 . Standard operation procedures (SOP) were developed and evaluated to minimize pre-analytical artefacts during biosample collection. Within the pretest studies different aspects concerning feasibility of sample collection/preparation [pretest 1 (a)] and quality control of biomarkers and proteome analyses were investigated [pretest 1 (b),

(c)]. Additionally, recruitment of study participants for specific projects and examination procedures of all study centres in a defined time period according to common stan- dards as well as transportation and decentralized storage of biological samples were tested (pretest 2). These analyses will serve as the basis for the biomaterial collection in the main study of the GNC starting in 2014. Materials and methods. Participants, randomly chosen from the population $(n=1000$ subjects recruited at ten study sites in pretest 1) were asked to donate blood, urine, saliva and stool samples. Additionally, nasal and oropharyngeal swabs were collected at the study sites and nasal swabs were collected by the participants at home. SOPs for sample collection, preparation, storage and transportation were developed and adopted for pretest 2. In pretest 2, 18 study sites ( $n=599$ subjects) collected biomaterials mostly identical to pretest 1. Biomarker analyses to test the quality of the biomaterials were performed. Results. In pretest 1 and 2 , it was feasible to collect all biomaterials from nearly all invited participants without major problems. The mean response rate of the subjects was $95 \%$. As one important result we found for example that after blood draw the cellular fraction should be separated from the plasma and serum fractions during the first hour with no significant variation for up to $6 \mathrm{~h}$ at $4^{\circ} \mathrm{C}$ for al analysed biomarkers. Moreover, quality control of samples using a proteomics approach showed no significant clustering of proteins according to different storage conditions. All developed SOPs were validated for use in the main study after some adaptation and modification. Additionally, electronic and paper documentation sheets were developed and tested to record time stamps, volumes, freezing times, and aliquot numbers of the collected biomaterials.

Discussion. The collection of the biomaterials was feasible without major problems at al participating study sites. However, the processing times were in some cases too long. To avoid pre-analytical artefacts in sample collection, appropriate standardisation among the study sites is necessary. To achieve this, blood and urine collection will have to be adapted to specific conditions of usage of liquid handling robots, which will be available at all participating study centres in the main study of the GNC. Strict compliance with the SOPs, thorough training of the staff and accurate documentation are mandatory to obtain high sample quality for later analyses. The so obtained biomaterials represent a valuable resource for research on infectious and other common complex diseases in the GNC.

\section{Machbarkeitsprüfung und Qualitätsentwicklung zur Gewinnung von Biomaterialien in den Pretest-Studien der Deutschen Nationalen Kohorte}

\begin{abstract}
Zusammenfassung
Hintergrund. Ein Hauptziel der Nationalen Kohorte ist es, Volkskrankheiten, wie z. B. Krebs, Diabetes, Infektions-, allergische, neurologische oder Herz-Kreislauf-Erkrankungen auf unterschiedlichen Ebenen besser zu verstehen: Es sollen Risikofaktoren für die Entstehungen dieser Erkrankungen identifiziert und Biomarker für ihre Früherkennung sowie präventive Maßnahmen entwickelt werden. Die Sammlung von Biomaterialien in Kombination mit Fragebogendaten und medizinischen Untersuchungen bilden wesentliche Komponenten der Studie.

Ziel der Arbeit. In 2 Pretest-Studien wurden zwischen 2011 und 2013 Biomaterialien von einer definierten Anzahl an Probanden gesammelt, um die Machbarkeit einer solchen Sammlung und die Probenqualität zu tes-
\end{abstract}

ten. In den Pretest 1 waren 10 und in den Pretest 218 Studienzentren involviert. Standardarbeitsanweisungen (SOPs) wurden entwickelt und evaluiert, um präanalytische Artefakte während der Probengewinnung zu minimieren. Während der 2 Pretest-Studien war die Überprüfung der Aspekte Machbarkeit der Probensammlung und -präparation sowie Qualitätskontrolle von Biomarker und Proteom wesentlich. Zudem wurden die Rekrutierung von Studienteilnehmern für spezifische Projekte und die Untersuchungsabläufe in allen teilnehmenden Studienzentren in einer bestimmten Zeit mit Blick auf die gemeinsamen Standards (Teil 2) getestet sowie Tests zum Transport und zur dezentralisierten Lagerung von biologischen Proben durchgeführt. Die Pretest-Studien dienen als Basis für die Biomaterialiensammlung in der Hauptstudie der Nationalen Kohorte, die 2014 startet

Material und Methoden. Zufällig aus der Bevölkerung ausgewählte Teilnehmer (im Pretest I $n=1000$, in 10 Studienzentren rekrutiert) wurden gebeten, Blut-, Urin-, Speichelund Stuhlproben zu spenden. Ferner wurden Nasen- und Rachenabstriche im Studienzentrum und von den Teilnehmern zu Hause gesammelt. SOPs für die Probensammlung, Probenverarbeitung, Lagerung und für den Transport der Proben wurden erarbeitet und nach dem Pretest 1 für Pretest 2 angepasst. Im Pretest 2 wurden von $n=599$ Teilnehmern in 18 Studienzentren Biomaterialien nahezu identisch zum Vorgehen in Pretest 1 gesam- 
melt. Anschließend wurden an den Proben molekulare Qualitätsanalysen durchgeführt. Ergebnisse. In Pretest 1 und 2 konnten alle genannten Biomaterialien von fast allen eingeladenen Probanden gesammelt werden. Die durchschnittliche Teilnahme am Biomaterialienprogramm lag bei $95 \%$, alle entwickelten SOPs waren umsetzbar und nach kleinen Anpassungen und Modifikationen für die Hauptphase der Studie einsetzbar. Ein wesentliches Ergebnis war z. B., dass die Abtrennung der zellulären Blutfraktion vom Serum und Plasma innerhalb der ersten Stunde nach Blutabnahme erfolgen sollte, um signifikante Variationen bei den hier untersuchten Biomarkern zu vermeiden. Zudem zeigte die

from 2011-2013 in two pretest studies ( 1 and 2 ) for feasibility testing. In pretest 1,1000 participants at ten study sites were invited to take part and in pretest 2 , 599 participants at 18 different study sites participated (- Table 1 and 2, study characteristics of pretest 1 and 2).

\section{Pretest study 1}

The pretest study 1 was used to test the (a) feasibility of sample collection and sample preparation, (b) quality control on the influence of time and temperature on biomarkers and (c) quality control of samples using a proteomics approach.

\section{Feasibility of sample collection and sample preparation}

The mean responses among the subjects were $99 \%$ for blood, $98 \%$ for urine, $93 \%$ for saliva, $93 \%$ for stool, $100 \%$ for nasal swabs, and $92.5 \%$ for oropharyngeal swabs. All biomaterials could be collected in sufficient amounts for further storage and analyses.

Processing of blood specimens. Regarding the processing of blood specimens, important time points concerning blood drawing (filling of seven blood tubes with total blood volume of $65 \mathrm{ml}$ ) and sample processing were analysed. The mean time for the blood draw was about $5 \mathrm{~min}$ (800 participants). The mean manual processing time from the end of centrifugation until dry ice storage was $6 \mathrm{~min}$ for serum (coagulation time $30 \mathrm{~min}, n=488$ participants) and $7 \mathrm{~min}$ for plasma (427 participants). Overall, the needed number of tubes (i.e. $3 x$ EDTA plasma $10 \mathrm{ml}, 2 \mathrm{x}$
Qualitätskontrolle in einem Proteomics-Ansatz keine signifikante Zusammenlagerung von Proteinen bei verschiedenen Lagerungsbedingungen nach Blutentnahme. Zusätzlich wurden elektronische und manuelle (Papier-) Dokumentationsbögen entwickelt und getestet, um Zeitstempel, Volumina, Einfrierzeiten und Anzahl an Aliquoten der gesammelten Biomaterialien zu erfassen.

Diskussion. Die Sammlung der Biomaterialien war ohne größere Probleme an allen teilnehmenden Studienzentren möglich. In einigen Fällen waren allerdings die Prozesszeiten zu lang. Zur Vermeidung präanalytischer Artefakte bei der Probengewinnung ist eine gute Standardisierung wesentlich. Um dies zu

serum $10 \mathrm{ml}$ ) could be filled for the needed amount of aliquots. Moreover, at the study site Augsburg the usage of a prototype of a liquid handling robot (STARlet, Hamilton Robotics) was tested for later automatisation of sample separation of blood (divided into serum, plasma, erythrocytes, buffy coat) and urine as well as aliquoting in small single-use aliquots. At the end of pretest I the work flows for blood and urine handling, respectively were tested and finalized for site-acceptance test.

Urine collection. For urine collection, the standard protocol for processing, automated analysis and storage required less than $60 \mathrm{~min}$, of which centrifugation took $15 \mathrm{~min}$. Standardized sampling, processing and immediate analysis of human urine were successfully established at multiple study centres. Potential bacterial contaminations that may influence all subsequent analyses in fresh and stored urine were assessed using the Siemens Clinitek Microalbumin 9 stix, followed by automated reading using a Clinitek Status Plus Device. The prevalence of noteworthy results for six commonly assessed urine parameters is shown in $\bullet$ Table 3.

Stool collection. For stool samples, the motivation for the feasibility study was to test the compliance rate of the participants as well as the potential of this material for pathogen-oriented, host-targeted and host-pathogen interaction research. The results of the latter one will be published separately. Overall, stool collection (native and DNA stabilized) was well accepted and performed by the vast erreichen, werden die Blut- und Urinverarbeitung an speziellen Bedingungen der Nutzung eines Liquid-Handling-Roboters ausgerichtet, der zur Hauptstudie an allen Studienzentren verfügbar sein wird. Die strikte Einhaltung der SOPs, eine intensive Schulung des Personals und eine exakte Dokumentation sind unerlässlich, um eine sehr gute Probenqualität für spätere Analysen zu erreichen. Diese Biomaterialien sind eine wichtige Quelle für die Infektionsforschung und die Erforschung anderer Volkskrankheiten.

majority ( $>90 \%$ ) of study participants in all study centres involved. Stool collection prior to the interview at the study centre rather than thereafter appears more acceptable since it involves a shorter transportation time. Storage at room temperature was performed by the majority of participants, with certain regional differences. The point in time of stool collection (either prior to the study centre visit or thereafter) appears to have no prominent effect on the general acceptance to collect this biospecimen.

The stool protocol allowed successful culture of faecal bacteria including multiresistant extended spectrum beta-lactamase producing enterobacteria [native stool tube (1) (manuscript in preparation)] and the extraction of PCR amplifiable DNA [DNA-stabilized tube (2)] as confirmed by the detection of $23 \mathrm{~S}$ rRNA genes of $H$. pylori and virulence factors of enteropathogenic E. coli (EPEC/EHEC) following the manufacturer's protocol.

Saliva collection. Saliva can be sampled sufficiently during a period of $1 \mathrm{~min}$ in comparison to $3 \mathrm{~min}$. Within this short time it was possible to get $1 \mathrm{ml}$ of saliva, if saliva flow was stimulated by chewing a tasteless paraffin wax (• Table 4$)$. The overall required time for the personnel in the laboratory, including pre- and postprocessing (providing material, informing the participant, measuring time and weight, aliquots and storage) was about $3 \mathrm{~min}$. The acceptance rate to donate saliva with the established SOPs was very high (• Fig. 2). 


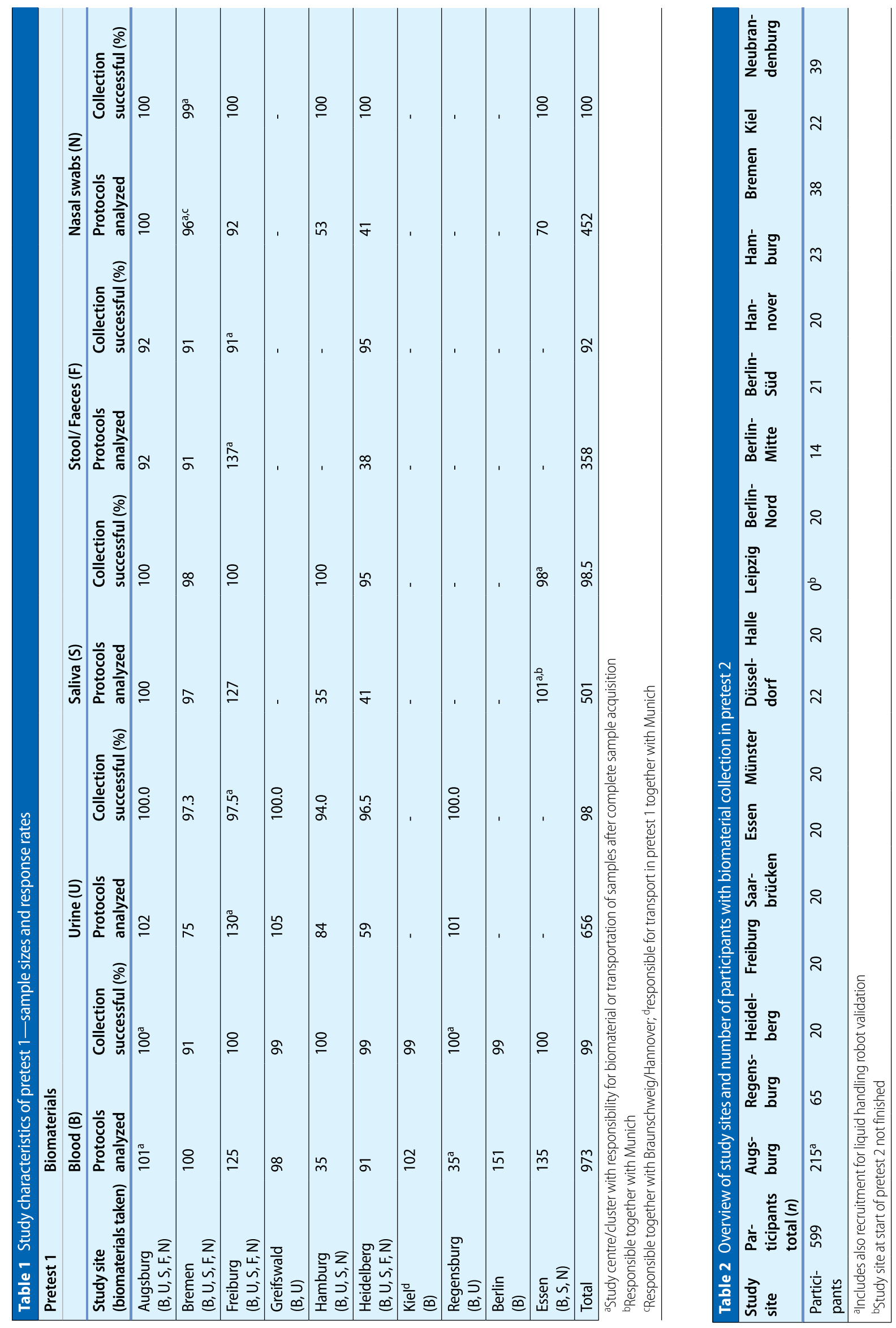


Table 3 Automated urine analyses: frequency of abnormal results (pretest 1)

\begin{tabular}{|c|c|c|c|c|}
\hline & $\begin{array}{l}\text { Overall } \\
(n=279)\end{array}$ & $\begin{array}{l}\text { Augsburg } \\
(n=48)\end{array}$ & $\begin{array}{l}\text { Freiburg } \\
(n=123)\end{array}$ & $\begin{array}{l}\text { Regensburg } \\
(n=108)\end{array}$ \\
\hline Kidney and bladder disease prevalence ${ }^{a}$ & $14.8 \%$ & $16.3 \%$ & $11.4 \%$ & $16.8 \%$ \\
\hline Erythrocyturia, $>50$ erythrocytes $/ \mu \mathrm{l}$ & $3.6 \%$ & $2.1 \%$ & $6.5 \%$ & $0.9 \%$ \\
\hline Leukocyturia, > 75 leukocytes/ $\mu \mathrm{l}$ & $2.5 \%$ & $6.3 \%$ & $1.6 \%$ & $1.9 \%$ \\
\hline $\begin{array}{l}\text { Microalbuminuria: albumine/ } \\
\text { creatinine ratio } 30-300 \mathrm{mg} / \mathrm{g}\end{array}$ & $18.6 \%$ & $6.3 \%$ & $26.8 \%$ & $14.8 \%$ \\
\hline Ketonuria & $1.4 \%$ & $4.2 \%$ & $1.6 \%$ & $0.0 \%$ \\
\hline Glucosuria & $1.1 \%$ & $0.0 \%$ & $2.4 \%$ & $0.0 \%$ \\
\hline Nitrituria & $1.8 \%$ & $2.1 \%$ & $2.4 \%$ & $0.9 \%$ \\
\hline
\end{tabular}

Table 4 Saliva weight in relation to the sampling time and procedure of stimulation

\begin{tabular}{|llllll}
\hline Time and Procedure & $\mathbf{n}$ & $\begin{array}{l}\text { Mean } \\
\text { weight }[\mathbf{g}]\end{array}$ & SD & $\begin{array}{l}\text { Minimum } \\
\text { weight }[\mathbf{g}]\end{array}$ & $\begin{array}{l}\text { Maximum } \\
\text { weight }[\mathbf{g}]\end{array}$ \\
\hline 1 Minute & 115 & 1.44 & 1.07 & 0.02 & 5.85 \\
\hline Unstimulated & 53 & 1.03 & 0.86 & 0.03 & 4.69 \\
\hline Stimulated & 62 & 1.79 & 1.12 & 0.02 & 5.85 \\
\hline 3 Minutes & 366 & 3.19 & 2.61 & 0.00 & 16.74 \\
\hline Unstimulated & 230 & 1.99 & 1.35 & 0.00 & 7.59 \\
\hline Stimulated & 135 & 5.21 & 2.95 & 0.69 & 16.74
\end{tabular}

Nasal/oropharyngeal swab collection. For nasal/oropharyngeal swabs, the feasibility of training study nurses to collect nasal and oropharyngeal swabs from the participants was examined. Results will be published separately (Akmatov et al., manuscript in preparation).

\section{Quality control: the influence of time and temperature on biomarkers}

In the GNC, processing of blood samples will be fully automated using a highthroughput liquid handling platform (Hamilton, Bonaduz, Switzerland). This platform includes a blood detection carrier for separating serum and plasma from the cellular fraction and a cooling carrier for storing the samples at $4^{\circ} \mathrm{C}$ until aliquoting them into storage tubes. To ensure high blood sample quality, the cellular fraction will be separated by centrifugation shortly after the blood draw, and serum und plasma aliquots will be frozen directly after processing. Within the feasibility study in pretest 1 , we tested whether an extended cellular incubation time and an intermediate cooling step influence the quality of serum and plasma samples. Specifically, the influence of time and temperature on sensitive biomarkers in whole blood, serum and plasma samples to identify acceptable time periods between blood drawing and processing were examined and sample handling protocols aimed at minimizing the development of pre-analytical artefacts were developed.

After a time period of $2 \mathrm{~h}$ between blood drawing and preprocessing, most analysed markers showed no significant variation, but ammonia levels increased from 70 to $96 \mu \mathrm{g} / \mathrm{dl}(p=0.21)$. While that specific finding did not reach formal statistical significance, perhaps due to the low sample size, it was concluded that the cellular fraction should be separated from the plasma and serum fractions during the first hour after blood draw. After separation from the cellular fraction, serum and plasma samples showed no significant variation for up to $6 \mathrm{~h}$ at $4^{\circ} \mathrm{C}$ for all analysed biomarkers [additionally analysed biomarker: $\mathrm{LDH}(p=0.7245)$, blood glucose $(p=0.93)$, potassium $(p=1.0)$, non-esterified fatty acids $(p=0.98)$ and vitamin B6 $(p=0.95)$ ].

\section{Quality control of samples using a proteomics approach}

The aim of this study was to investigate protein/peptide stability with a shotgun proteomics approach including labelfree quantification during different sample handling and storage protocols, in order to specify optimal SOPs for the collection and storage of plasma samples within the GNC. In our study blood was centrifuged, $3 \mathrm{ml}$ EDTA-plasma extracted and cooled in ice-water. Samples were then either immediately processed for mass spectrometry or snap frozen with liquid $\mathrm{N}_{2}$, or frozen at $-80^{\circ} \mathrm{C}$ or stored for $3 \mathrm{~h}$ in ice-water before they were snap frozen with liquid $\mathrm{N}_{2}$, or frozen at $-80^{\circ} \mathrm{C}$ or stored at room temperature for $24 \mathrm{~h}$. Processing of samples for mass spectrometry followed our established ProteoMiner protocol [4], which reproducibly depletes high abundant proteins in order to increase sensitivity of peptide detection. Processed samples were measured on a XL-Orbitrap LTQ (Thermo Fisher Scientific) with a top-10 method and a LC-gradient for complex samples (for details see [4]). Data were analysed using a software for label-free quantification (Progenesis LC-MS, Nonlinear Dynamics; [5]) and protein contents of the tested conditions quantified. More than 150 proteins could be identified across all plasma samples. Of these, nearly 90 proteins could be reliably quantified with $>2$ peptides. The average technical variability, over all conditions tested, was calculated to be $10 \%$. The majority of detected proteins $(>90 \%)$ did not vary significantly between the tested conditions, while a few proteins like fibulin-1, a-1-antichymotrypsin or vitamin Kdependent protein $\mathrm{Z}$ showed significant changes in abundance between different storage conditions tested. However, no significant clustering of proteins according to different storage conditions could be detected.

\section{Pretest study 2}

The pretest study II had two primary objectives:

1. to recruit study participants for the specific projects (particularly in part 1) and

2. to test the recruitment and proposed examination procedures in all study centres participating in the main study of The German National Co- 
hort in a defined time period according to common standards (part 2).

Moreover the aspect of transportation and decentralized storage of biological samples was investigated (starting in pretest 1).

Blood collection. The mean duration of blood collection was 4.7 min (median $3 \mathrm{~min}$ ) for seven tubes with a total volume of $65 \mathrm{ml}$ and the processing time (end of blood collection until the end of centrifugation) for EDTA-anticoagulated blood was $24 \mathrm{~min}$ (median $19 \mathrm{~min}$ ) and for serum it was $77 \mathrm{~min}$ (median $64 \mathrm{~min}$ ). Overall, the mean time from the end of centrifugation until freezing of aliquots across study sites was $106 \mathrm{~min}$ (median $40 \mathrm{~min}$ ) for EDTA-plasma and it was $114 \mathrm{~min}$ for serum (median $47 \mathrm{~min}$ ). For processing the CPT-anticoagulated blood for isolation of mononuclear cells, the study sites needed a mean of $147 \mathrm{~min}$ from the end of blood collection until freezing the cells (median $115 \mathrm{~min}$ ).

Urine collection. For $99 \%$ of the participants, the collection of urine was possible without any problems. The mean volume was $61 \mathrm{ml}$ (median $62 \mathrm{ml}$ ) and the average duration for sample processing (end of centrifugation until freezing of aliquots) was $109 \mathrm{~min}$ (median $29 \mathrm{~min}$ ).

Saliva collection. The collection of saliva was possible for $98 \%$ of the participants without any problems. The mean retrieved volume was $0.998 \mathrm{ml}$ (median $1.0 \mathrm{ml}$ ) and the mean sample processing time (end of centrifugation until freezing of aliquots) was $19 \mathrm{~min}$.

Stool collection. Stool was successfully collected from $95 \%$ of the participants; $49 \%$ of the stored samples were transported to the study site. The mean time from sample collection to freezing at the study site was $316 \mathrm{~min}$.

Anterior nasal swab collection. Anterior nasal swabs were collected successfully for $96 \%$ of the participants. The mean time from the end of sample collection until freezing at $-80^{\circ} \mathrm{C}$ was $130 \mathrm{~min}$ (median $75 \mathrm{~min}$ ). Detailed results will be pub- lished separately (Akmatov et al., manuscript in preparation). No major problems occurred during sample collection at the study sites. Minor problems related to technical or procedural aspects were resolved by phone call or email to the project coordinator in Munich.

Transportation and decentralized storage of biological samples. General conditions for transporting biomaterials using dummy samples on dry ice were tested in pretest 1 . In pretest 2 , the transportation of real samples obtained from liquid handling testing at the Augsburg study centre was tested: (I) different package sizes and amounts of dry ice per parcel and (II) different temperature logger systems to find the ideal candidate for further usage. The results of the tests show that standardization of packaging was mandatory. One logistic company should deliver parcels and dry ice to the study sites on defined days every two weeks according to a preplanned logistic plan. It was also necessary to use outer packaging such as a box/carton to cover the styrofoam and to fasten the data logger in order to prevent loss or damage during transportation.

Boxes were picked up between 11 a.m. and 5 p.m. at the study centres and delivered between 8 a.m. and 10 a.m. to the study centre in Munich. During shipment, there was a loss of approx. 4-6 kg dry ice. Maximum temperature $\left(-74^{\circ} \mathrm{C}\right)$ was measured on top of the samples, when the dry ice did not cover the samples completely. In two cases, the foamed polystyrene boxes ( $4 \mathrm{~cm}$ thickness) of a package without surrounding paperboard container had a leakage/were broken. No "damage" was detected when a surrounding paperboard box and insulation layers of $6 \mathrm{~cm}$ were used.

The usage of a data logger (CIK solutions) with external sensors (TREL-8) was recommended; the sensor was easily placed between the boxes/racks inside the parcel for temperature measurement. Upon arrival the logger unit was removed from the parcel because of its external installation and checked immediately for correct temperature during transport.

\section{Discussion and conclusion}

Both pretest studies were conducted to obtain valid SOPs for biomaterial collection for the main study of the German National Cohort to reduce artefacts resulting from sub-optimal sample retrieval, preparation, or storage and thereby store samples with the best quality for future analysis. In pretest 1 , the participating study sites were able to work with the SOPs developed and to fill in the questionnaires (biomaterial protocols) for later evaluation. Problems were reported directly to the responsible authors of the SOPs. After this, the SOPs and the documentation system were adapted and revised for pretest 2 (• Fig. 1, example for SOP collection, so called "Organisationshandbuch"). The collection of the biomaterials was feasible without major problems at all participating study sites. The processing times were in some cases too long. One workable approach to shorten sample processing times would be to employ well-trained and experienced staff with sample handling routine and optimized time management.

The quality of biomaterials as well as the diagnostic of biomarkers in later analyses both depend on many different factors [10]. The test of some quality factors was an important point in our studies. However, deviations in results between the study sites were observed, as shown in - Table 3 for urine analytics. False-positive and false-negative results are common in point-of-care diagnostics and could be a result of wrong or incorrect handling of the reagent strips. Moreover, storage conditions of the test strips usage, expiration date, and exposure to sunlight, moisture, heat, or cold may have an influence on the results. The specific reagents should be read at the appropriate time after dipping in urine, as recommended by the manufacturer. The strip should not be dipped for more than a second in the urine, and excess urine should be blotted off on the edge of absorbent paper to prevent mixing of reagents. A midstream urine specimen also reduces contamination [11]. The latter points could only be avoided by good trained staff but not completely excluded. 
The results from the quality control of the influence of time and temperature on biomarkers (part $b$ in results section) provided relevant information regarding (1) identification of an acceptable time period between blood draw and analysis and (2) clarification of temperature conditions that result in stability of blood parameters over time (room temperature or $4{ }^{\circ} \mathrm{C}$ ).

For our proteomics approach (pretest 1 , part c) we found that results were in good agreement with literature data [9]. Global stability of a majority of plasma proteins for mass spectrometry-based analyses could be shown. Furthermore it was possible to identify potential marker proteins which change under different sample handling and storage conditions and can thus be used as indicative markers to control sample quality during long-term storage. As a follow-up procedure, targeted analyses of absolute protein intensities could be established using AQUA peptides for selected protein marker candidates.

For documentation of the pre-analytical parameters such as time stamps, volumes, aliquots and feasibility of sample retrieval, an appropriate working documentation sheet is mandatory, such as a Laboratory Information Management System (LIMS, Kairos), which is actually set-up and will be used from all study sites in the main phase.

To avoid pre-analytical errors and artefacts in sample collection, high standardisation among the study sites is essential. Strict compliance with the SOPs is mandatory to obtain the best sample quality for later analyses. However, thorough training of staff is as important as exact SOPs. Accurate documentation is also a valuable tool to assess the quality of a sample concerning its capability to provide plausible analytical results. In the main study of the GNC SOPs for blood and urine collection will have to be adapted to specific conditions of usage of liquid handling robots, which will be available at all participating study centres. The planned liquid pipetting robot was only available at the study site Augsburg as a proto-type for development and testing of hardware and software configuration during the pretests. At the other study sites samples had to be pipetted manually. The conditions for transport of samples were also directly corre- lated with sample quality. The use of ultralow temperatures (dry ice) for transport to avoid freeze-thaw cycles, the usage of temperature data logger to record the temperature over the time and the correct packaging and filling of the transport boxes were regulated by SOPs to avoid any possible artefacts generated at this critical step. A correct pre-analytic beforehand does not pay if artefacts occur during or after transportation and/or later storage.

Taken together, the German National Cohort will collect-in contrast to other comparable large epidemiological studies $[6,7]$ - high quality biomaterials by adhering to the following principles:

- prompt and complete separation, ideally within one hour after collection, of all particulate components of full blood to obviate the above detailed cell-derived artefacts,

- no delay in aliquoting and freezing to avoid enzymatic degradation during prolonged transportation at $4^{\circ} \mathrm{C}$ or higher and

- volumes small enough (less than $300 \mu \mathrm{l})$ to guarantee single use only as opposed to repeat thaw-freeze cycles necessarily implicated in the storage of larger volumes.

This will be guaranteed by the following procedures:

- Local processing of blood, urine, and other biomaterials as opposed to a centralized one, complete enough to reach the level of ready-prepared small aliquots that can be transported to the central store on dry ice in the deep-frozen state which obviates the enzymatic disintegration incurred upon prolonged exposure to $4^{\circ} \mathrm{C}$ or higher.

- Automation of all steps in preparation, storage, and retrieval of stored materials, promoting strict adherence to standard operation procedures (SOPs), maximizing reproducibility, and preventing artefacts that in manual processing inevitably occur on the long run due to individual failure. Thus, each of the 18 study centres will be equipped with a liquid handling platform.

- Storage of biomaterials from all participants throughout Germany in one central automated biorepository (located in Munich) and decentralized back-up storage at different places in Germany.

- Storage of many but rather small volume aliquots to avoid freeze-thaw cycles and thereby to increase sample quality.

\section{Corresponding address}

\section{Prof. Dr. T. Illig}

Hannover Medical School, Hannover Unified Biobank (HUB), Feodor-Lynen-Str. 15

30625 Hannover

illig.thomas@mh-hannover.de

Acknowledgments. The authors thank all people at the study sites who were involved in the studies. This project was conducted in the context of the pretest studies of the German National Cohort (www. nationale-kohorte.de). These were funded by the Federal Ministry of Education and Research (BMBF), Förderkennzeichen 01ER1001/A-I, 01ER1203 and were supported by the Helmholtz Association as well as participating universities and Institutes of the Leibniz Association. AK and ONG were funded by the Emmy Noether Programme of the German Research Foundation (KO 3598/2-1 to AK).

\section{Compliance with ethical guidelines}

Conflict of interest. A. Kühn, A. Nieters, A. Köttgen, O.N. Goek, K. Michels, U. Nöthlings, G. Jacobs, C. Meisinger, F. Pessler, M.F. Akmatov, J. Kühnisch, S. Moebus, E. Glocker, S. Naus, M. Keimling, M. Leizmann, J. Linseisen, H. Sarioglu, C. von Toerne, S.M. Hauck, H. Wallaschofski, H.E. Wichmann and T. Illig state that there are no conflicts of interest.

All studies on humans described in the present manuscript were carried out with the approval of the responsible ethics committee and in accordance with national law and the Helsinki Declaration of 1975 (in its current, revised form). Informed consent was obtained from all patients included in studies.

\section{Glossary}

\section{AQUA peptide}

technology in proteomics. A synthetic tryptic peptide corresponding to a peptide of interest. Each AQUA peptide incorporates one stable isotope labeled amino acid, creating a slight increase (6-10 daltons) in molecular weight. When mixed, the native peptide and the synthetic AQUA Peptide elute together chromatographically, migrate together electrophoretically, and ionize with the same intensity. However, by mass spectrometry, the native peptide and the synthetic AQUA Peptide are easily distinguished. 
Artefact

errors resulting from incorrect sample handling or collection, e.g. from blood drawn too rapidly using blood monovettes or the occurrence of freeze-thaw cycles [3].

\section{Biobank}

an organisation that collects, stores and analyses biospecimens, making the results available to research organisations investigating new treatments for diseases [3].

\section{Biomaterial}

means any specimen, $S D, C D, S M D$ or progeny [12].

\section{Biomarker}

Biomarkers isolated from patient specimens may be DNA variants, epigenetic markers, transcripts, proteins or metabolites. The time between collection of the specimen and processing for long-term storage must be minimized to limit time and temperaturedependent loss of potential biomarkers [2].

\section{Biorepository}

a repository (storage centre) for biological materials.

\section{Buffy coat}

After centrifugation of EDTA plasma tubes, one can distinguish a layer of clear fluid (the plasma), a layer of red fluid containing most of the red blood cells, and a thin layer in between (the buffy coat). Making up less than $1 \%$ of the total volume of the blood sample, the buffy coat (so-called because it is usually buff in hue), contains most of the white blood cells and platelets. The buffy coat is used, for example, to extract DNA from the blood of mammals.

\section{Complex derivative $(C D)$}

any derivative prepared through complex multi-step laboratory manipulations from a specimen or SD, with or without addition of chemical substances, such as isolated viruses, isolated bacteria, metabolites, DNA, RNA, PBMCs, fibroblast culture, sorted cells and FFPE tissue [12].

\section{Liquid handling robot/platform}

used in automation of chemical or biochemical laboratories. It is a robot that dispenses a selected quantity of reagent, samples or other liquid to a designated container.

\section{Long-term storage}

Storage of biomaterials for later analyses at ultra-low temperature, e.g. liquid nitrogen, to avoid/slow down chemical and physical reactions.

\section{Participant}

also called a human subject or an experiment, trial, or study participant or subject, is a person who participates in human subject research by being the target of observation by researchers.
Phenotyping

the construction, recording and analysis of phenotypes.

\section{Pre-analytics}

refers to all processes that occur prior to the actual laboratory analysis, starting from sample collection (e.g. blood, saliva or urine), to sample stabilization, transport, and storage. Features of biospecimen quality.

Pretest study/feasibility study an analysis of the viability of an idea.

Progeny

any unmodified descendant from a renewable $C D$, such as virus from virus, cell from cell, or organism from organism. [12].

\section{Proteomics}

the large-scale study of proteins, particularly their structures and functions.

\section{Quality control}

the system of technical activities that measures the attributes and performance of a process, assay, item, or product against defined standards to verify that the stated requirements are fully met.

Simple derivative (SD)

any derivative prepared by simple laboratory manipulations from a specimen, without addition of chemical substances, such as plasma, serum, buffy coat, homogenized tissue or urine pellet [12].

\section{SOP}

standard operation procedure, detailed, written instructions to achieve uniformity of the performance of a specific function.

Substantially modified derivative (SMD) a derivative of an $\mathrm{SD}$ or $\mathrm{CD}$ whose molecular structure and/or its associated molecular pathways are not found in the source specimen, SD or $C D$, such as immortalized cell lines, iPSCs, genetically modified micro-organisms and hybridomas [12].

\section{References}

1. The German National Cohort. www.nationale-kohorte.de. Accessed 2014

2. Coriell Institute for Medical research. www.coriell. org. Accessed 2014

3. ISBER (2012) Best practices for repositories. Biopreserv Biobank (BIO) 10(2)

4. von Toerne C, Kahle M, Schäfer A et al doi:10.1021/ pr3009836

5 Hauck SM, Dietter J, Kramer RL et al doi:10.1074/ mcp.M110.001073

6 Peakman TC, Elliott P doi:10.1186/gm193

7. Peakman TC, Elliott P doi:10.1093/ije/dyn019

8. National Cancer Institute (2011) Best practices for biospecimen resources. http://biospecimens.cancer.gov/practices/. Accessed 2014

9. Qundos U, Hong MG, Tybring G et al doi:10.1016/j. jprot.2013.04.020
10. Betsou F, Gunter E, Clements J et al doi:10.1016/j. jmoldx.2012.06.008

11. Patel HP doi:10.1016/j.pcl.2006.02.004

12. Integrated biobank of Luxembourg (IBBL). www. ibbl.lu. Accessed 2014 